\title{
Equivalence of male and female performance on a tactuospatial maze
}

\author{
GERI R. ALVIS, JEANNETTE P. WARD, and DEANNA L. DODSON \\ Memphis State University, Memphis, Tennessee
}

\begin{abstract}
Sex differences in performance of a tactuospatial finger-maze task were assessed in 28 male and 32 female right-handed college undergraduates. The subjects performed the task with their nondominant left hand, and were trained to one error-free trial within specified time limits. Cognitive tests were administered to assess vocabulary, word fluency, and spatial relations capabilities. The results failed to indicate any significant sex differences in performance on the tactuospatial maze in terms of mean errors, number of trials, and trial latencies, or on any of the cognitive tests. The findings strengthen proposals that male superiority in spatial ability may not be as substantial as commonly accepted, and that sex differences in performance may depend on the particular components of spatial ability that are measured in specific tasks.
\end{abstract}

According to some recent reviews (Caplan, MacPherson, \& Tobin, 1985; Linn \& Peterson, 1985), the reputed male advantage in spatial ability may be limited to some visuospatial tasks. The variety of tasks employed to measure spatial ability has yielded much inconsistent data. For example, both the Porteus Maze Test and the Standardized Road-Map Test of Direction Sense assess visuospatial ability but have produced contradictory and noncorrelated results (Caplan et al., 1985). Similarly, studies that have examined sex differences in performance of different tasks requiring tactuospatial functioning have resulted in inconsistent data: male superiority has been noted in some cases (e.g., Dawson, 1981), but no sex differences or even a female advantage has been found in others (e.g., Biersner, 1980). This study presents additional data regarding sex differences in the performance of a tactuospatial task.

\section{METHOD}

\section{Subjects}

Twenty-eight male and 32 female right-handed psychology students at Memphis State University participated as subjects for extra credit; the task had been described as involving a manual learning task and some written tests.

\section{Test Materials and Apparatus}

The Lateral Dominance Questionnaire (Lawson, Goldstein, \& Musty, 1975) assesses the performance of 12 tasks with the dominant hand (8), foot (2), or eye (2). Lateralization of 8 or more items to the right was required for subjects to be classified as right-handed; these subjects also had identified themselves as right-handed and wrote with the right hand.

A plywood finger-maze that measured approximately $27 \mathrm{~cm}$ long, $21 \mathrm{~cm}$ wide, and $2 \mathrm{~cm}$ thick was used to examine tactuospatial performance. One pathway with 5 cul-de-sacs led from start- to goalbox. The pathway and the circular start- and goalboxes were approximately $2 \mathrm{~cm}$ and $3 \mathrm{~cm}$ wide, respectively.

The abbreviated Shipley Vocabulary Test (Shipley, 1967), the Verbal Fluency Test (Thurstone, 1962), and the Spatial Relations subtest of the Differential Aptitude Tests (DAT; Bennett, Seashore, \& Wes-

Correspondence may be addressed to Jeannette P. Ward, Department of Psychology, Memphis State University, Memphis, TN 38052. man, 1974) were employed to assess the subjects' cognitive and visuospatial abilities.

\section{Procedure}

In individual sessions, the subjects were administered the Lateral Dominance Questionnaire. Then, after the subjects were blindfolded, the maze was uncovered. The task was explained as involving learning to run the maze from start- to goalbox one time without entering any cul-de-sac, with accuracy instead of speed as the critical performance measure.

The subjects included in the present report were participants in an ongoing study of tactuospatial functioning, who had been assigned to one condition in which each subject performed the finger-maze task with the nondominant (left) hand. This procedure should have maximized tactuospatial ability, since tactile as well as spatial functioning is predominantly under right hemisphere control, especially in right-handers (see e.g., Bryden, 1982; Corballis, 1983).

The experimenter initially guided the index finger of each subject's left hand through the entire maze one time. For subsequent trials, the subject's finger was placed in the startbox, and the beginning of each trial was prompted with the instruction "start." Trials continued until one error-free run was achieved. Each single trial was limited to $5 \mathrm{~min}$, and there was a 10-min time limit for achieving one error-free run. The total number of trials and the time for each trial were recorded. For each trial errors were recorded, whenever the subject's finger entered any cul-de-sac; repeated errors were scored.

After completion of the finger-maze task, the Shipley Vocabulary Test, Verbal Fluency Test, and DAT Spatial Relations subtest were administered, in this sequence, with the appropriate instructions and the applicable time criteria. The scores included the number of correctly identified words and the number of spatial relations problems solved, plus the number of words generated.

\section{RESULTS}

The maze performances of females and males did not differ significantly in terms of mean errors [female $X=$ 22.4 , male $X=23.6 ; t(58)=-.28$ ], total number of trials [female $X=7.2$, male $X=7.5 ; t(58)=.31$ ], or trial latencies [female $X=238.3$, male $X=233.7 ; t(58)$ $=.14]$.

There were no significant differences between the mean scores of males and females on the three cognitive tests: Shipley Vocabulary Test (female $X=30$, male $X=30.4$; 
$t(58)=45$ ); Verbal Fluency Test (female $X=43.8$, male $X=40.7 ; t(58)=.97)$; DAT Spatial Relations subtest (female $X=35$, male $X=35.3 ; t(58)=.18$ ).

Tests for homogeneity of variance showed only nonsignificant differences between the two groups on all measures.

\section{DISCUSSION}

The comparability of the two groups' performances on all cognitive tests suggests that the demonstrated female equality in left-handed fingermaze acquisition performance is unlikely to be due to a general superiority in educational level or cognitive capabilities of females in this study. Instead, the findings seem to reflect an equivalent tactuospatial capability of males and females in this particular task.

Since males were not found to perform in a manner superior to that of females, despite a previously mentioned apparent advantage on maze tests associated with visual functioning, tactuospatial and visuospatial abilities appear to represent separable components of spatial ability. Such a distinction between tactuo- and visuospatial maze performance abilities is already suggested by Orbach's (1959) early finding that bilateral striate cortex lesions in monkeys differentially affected performance on stylus and walk-through mazes.

Certain nonmaze tactuospatial tasks in which a male advantage has been noted, as in Dawson's (1981) finding that male right-handers performed better than females in visual identification of objects felt with the left hand, may rely on visual rather than on tactual functioning as the primary determinant of efficient task performance. By contrast, as in the present study, Biersner's (1980) finding of no sex differences in left- or right-handed finger-maze acquisition probably reflects the primary tactuospatial functioning involved in this task more directly. And the suggestion, made in Biersner's study, that an observed female advantage in right-handed performance improvement may reflect better lefthemispheric sequential tactuomotor skills in association with the more highly developed verbal-analytical ability of females implicates cognitive strategy use as an additional possible influence on the efficient performance of this task.

The equivalent performances of males and females on the DAT Spatial Relations subtest and on similar tests concur with Linn \& Peterson's (1985) analysis that only minor and generally insignificant sex differences have been found on it and similar measures; they attribute this to the probable use of diverse cognitive strategies in conjunction with the spatial visualization and mental rotation skills required in performance of these tests. With only small sex differences in performance on such measures, demonstrations of comparable performances of males and females would then be expected in many studies with smaller subject samples than the very large ones relied upon by DAT norms and other reports where a male advantage on the DAT Spatial Relations subtest has been indicated.

Demonstrations of sex differences in spatial ability thus appear to depend to a large extent on the particular tasks and procedures that are used in assessment, and on the specific sensory and cognitive functions and processes that may be involved. Further research is of course needed to ascertain the indicated equivalence of males and females in performance of pure tactuospatial tasks. However, the data reported here agree with and strengthen suggestions (Caplan et al., 1985; Linn \& Peterson, 1985) regarding multiple factors of spatial ability (its separate tactual, visual, and other aspects) that will require more precise investigation before firm conclusions about possible sex differences may be drawn.

\section{REFERENCES}

Bennett, G. K., Seashore, H. G., \& Wesman, A. G. (1974). Differential Aptitude Tests. New York: Psychological Corporation.

BIERSNER, R. J. (1980). Sex differences in right- and left-hand tactuomotor acquisition practice. Perceptual \& Motor Skills, 50, 986.

BRYDEN, M. P. (1982). Laterality: Functional asymmetry in the intact brain. New York: Academic Press.

Caplan, P. J., MacPherson, G. M., \& Tobin, P. (1985). Do sexrelated differences in spatial abilities exist? A multilevel critique with new data. American Psychologist, 40, 786-799.

Corballis, M. C. (1983). Human laterality. New York: Academic Press.

Dawson, G. D. (1981). Sex differences in dichaptic processing. Perceptual \& Motor Skills, 53, 935-944.

Lawson, R. B., Goldstein, S. G., \& Musty, R. E. (1975). Experiments in psychology: Laboratory manual and kit to accompany Principles and methods of psychology. New York: Oxford University Press.

LinN, M. C., \& Peterson, A. C. (1985). Emergence and characterization of sex differences in spatial ability: A meta-analysis. Child Development, 56, 1479-1498.

ORBACH, J. (1959). "Functions"' of striate cortex and the problem of mass action. Psychological Bulletin, 56, 271-292.

SHIPLEY, W. C. (1967). Manual: Shipley Institute of Living Scale. Los Angeles: Western Psychological Services.

Thurstone, L. L. (1962). Primary mental abilities. Chicago: Scientific Research Associates.

(Manuscript received May 27, 1988.) 